Article

\title{
Projectability and Heritage Management of Design Knowledge: A Grass-Roots Artefact Perspective of a Longitudinal Research Project for Knowledge Management System Innovation
}

\author{
Ulrich Schmitt
}

Citation: Schmitt, U. Projectability and Heritage Management of Design Knowledge: A Grass-Roots Artefact Perspective of a Longitudinal Research Project for Knowledge Management System Innovation. Sustainability 2021, 13, 13033. https: / / doi.org/10.3390/su132313033

Academic Editors:

Opdenakker Raymond,

Daniel Pacheco Lacerda,

Cuijpers Carin and Aline Dresch

Received: 5 September 2021

Accepted: 28 October 2021

Published: 25 November 2021

Publisher's Note: MDPI stays neutral with regard to jurisdictional claims in published maps and institutional affiliations.

Copyright: (C) 2021 by the author. Licensee MDPI, Basel, Switzerland. This article is an open access article distributed under the terms and conditions of the Creative Commons Attribution (CC BY) license (https:// creativecommons.org/licenses/by/ $4.0 /)$
Business School, University of Stellenbosch, Bellville 7535, South Africa; schmitt@knowcations.org

\begin{abstract}
This article expands on design science-research (DSR) publications which-based on current knowledge management systems (KM/KMS) and practices-are conceptualizing and prototyping a novel more generative and knowledge-worker-centric approach just presented as a desirable sustainable KMS vision. The perspective taken follows up on recent systematic literature reviews and content analysis studies reporting on the poor knowledge accumulation and evolution in the design, information science, and KM disciplines. Proposed remedies and initiatives are pitched against the novel KMS development case with its longitudinal stream of research output. As the design and creation of complex innovative artefacts facing 'wicked' challenges are seldom complemented by concurrent research papers, rare insights are offered of how similar longitudinal DSR or KMS projects may be structured and of how the related domain's heritage knowledge base and its fitness-for-useand-evolution may be strengthened. Due to the cycles and progression of its prior publications, this case study is particularly suited to contribute to cumulative research synthesis and, hence, further focusses on the recently proposed notions of projecting and projectability for evaluating distances between actual real-world environments and future possible-world application-ecosystems-a perspective which may become essential acceptance criteria for publishing in DSR-related conferences and journal publishing outlets.
\end{abstract}

Keywords: knowledge management; knowledge management system; knowledge heritage; artefact; projectability; design science research; axiomatic design; CK-theory; sustainability vision

\section{Introduction to the Significance of Longitudinal Studies for Design Knowledge}

The notion of 'Standing on the Shoulders of Giants' implies that scholarship usually "is an inherently social activity, involving a wide range of public and private interactions within a research community. Publication, as the public report of research, is part of a continuous cycle of reading, writing, discussing, searching, investigating, presenting, submitting, and reviewing" [1].

The underlying research paradigms may combine reactive behaviors (in natural and social sciences for understanding reality) and proactive design (in engineering and technology for creating supportive artefacts) [2]. Complex projects of the latter category may typically embody "longitudinal streams of research" activities and outputs where evolving contributions need to be presented and published at appropriate times including reporting on "early visions of technology impact" as well as "impact on users, organizations and society" [3].

However, although the body of design science research (DSR) is growing, the "accumulation and evolution of design knowledge" (DK) has not taken shape: "Most contributions rather stand on their own feet" triggering a pressing need for "guidance on how to position design knowledge contributions in wider problem and solution spaces" [4].

Looking at the closely related trans-disciplinary domain of knowledge management systems (KM/KMS), similar concerns have emerged as stated by two exploratory IS (Information Systems) and KM studies [5,6] to be referred to. 
As this Special 'Sustainability' Issue "Designing Artifacts/Tools for Increasing Sustainability" seeks out innovative artifacts with their inherent knowledge contributions for driving effective design, implementation, and application agendas [7], this article addresses DK's cumulative synthesis for serving the DSR discipline to be exemplified by the case study of a novel Personal/Generative KMS development project-in-progress. As a longitudinal stream of DSR/KM research with a series of peer-reviewed publications, the emphasis is on how its design and diffusion approach has already integrated currently contemplated measures to strengthen the DSR domain and paradigm.

The research objective of this article is, thus, to follow up on the concerns and guidance mentioned above and demonstrate- by presenting the novel KMS project case- the feasibility of the suggested remedies, including projections and horizontal and vertical projectability options in the DSR context. To differentiate the novel personal/generative from the conventional organizational KMS approach the acronyms PKMS and OKMS are used.

The article commences with current gaps and risks affecting the DSR body of literature (2), and the prospective guidance based on the notions of fitness, confidence, and projectability (3), followed by general artefact, evaluation, diffusion, and needs issues (4), the PKMS case study (5), a discussion on how Sections 2 and 3 interrelate with Sections 4 and 5 (6), and Conclusions (7).

\section{Current Gaps and Risks Affecting the DSR and KMS Bodies of Domain Knowledge}

Mariano et al. assessed the role of artefacts in the KM field over 18 years (1997-2015). Their systematic literature review (101 articles from seven journals) shows a lack of cumulativeness, consistency, and integration (of existing contributions) featuring a dominance of empirical over conceptual work (75\%) and a focus on an organizational level of analysis $(72 \%)$ with the remainder divided among individual, group, and inter-organizational levels. Suggested research directions include developing consistent sets of definitions and terminology, refining theoretical treatments of artifacts, specifying knowledge processes, and investigating the influence of managerial actions [6].

Information System Design Theories (ISDTs) are especially important for accumulating design-oriented knowledge by integrating meta-requirements/design, kernel theory, and testable propositions. Schuster et al. "explored how follow-up research has tested and extended ISDTs" (1992 to 2014). Focusing on seven ISDTs as a base for forward searches, 208 citing papers (CPs) within and beyond IS journals were identified. Their qualitative citation content analysis concluded that only two ISDTs were either tested or extended (by just 3 and $7 \mathrm{CPs}$ ) uncovering an alarming paucity of progressive follow-up research. As a remedy ISDT authors are asked to suggest paths for instantiation and possible extensions; follow-up testing/extending research should also be encouraged by authors, editors, and funding bodies based on transparent and precise advancements [5].

De Sordi et al.'s recent 'DSR in Practice' study "What Can We Learn from a Longitudinal Analysis of the Development of Published Artifacts" identified and analyzed 92 articles (presenting a variety of DSR-developed artifacts of intangible nature from 2013-2018 indexed in the Web of Science (WoS) databases) and another associated "60 articles with preceding or subsequent actions". The results focus on their longitudinal project evolution including the clustering of entry point opportunities, activity cycles (precedence hierarchy), and shortcomings (e.g., evaluation, design pilot versus design release instantiations, or formulation of mid-range design theory) [8].

De Sordi et al. utilized 57 articles (62\% of their sample) to analyze the transitions between artefacts; each of them either had one preceding (47), one subsequent (seven), or one of each type (three) of articles. Although these 60 related articles were more widely sourced (incl. Google Scholar and Research Gate) and some of the 92 sampled projects may still be ongoing (and yield further succeeding publications), the concerns regarding the cumulative development of IS and KM knowledge referred to earlier [5,6] seem to equally apply to the realm of DSR. 
The results of the few transition cases identified show a clear one-way path (Figure 1) from Constructs to Models to Methods and Instantiations with the latter acting as the "terminal artifact in terms of a DSR project".

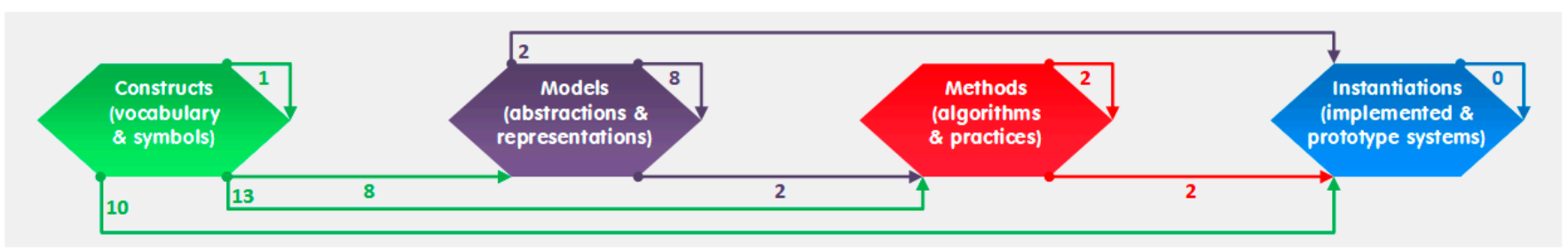

Figure 1. Number of Transitions between Artefact Types in 'DSR in Practice' Study [8].

Given that "design is inherently an iterative and incremental activity with no welldefined stopping rules" [9] and that the "engineering research culture places explicit value on incrementally effective applicable problem solutions" [10], this one-directionality presented in the combined sample is unexpected, even more so as "an instantiation may [also] actually precede the complete articulation of its underlying constructs, models, and methods" [9]. "Considering the exponential growth observed in articles using the DSR approach", De Sordi et al. conclude that "the analysis of nascent theories through DSR projects configures an opportunity for the continuity of [their] research" [8].

De Sordi et al.'s study provided the initial motivation for this article, and its logic is to be applied to show that the PKMS case study-if one of its publications had been included in the analysis-would have provided quite an outlier in its findings.

\section{Prospective Guidance for Cumulative Design Knowledge Development}

Concerned about this limited accumulation and evolution of DK (problem space referring to the shortcomings identified in Section 2), Vom Brocke et al. point out the different maturity levels DK components may assume which could considerably improve if reuse, compositions easing reuse or tackling more complex challenges, and post-project updates maintaining the DK's currency and timeliness could be strengthened (solution space) [4]. An obstacle, however, persists due to the inadequate conceptual and methodological support to incentivize the necessary buy-in of design science researchers for sufficient impact.

Initiatives of consulting, empathizing, and strategizing with relevant stakeholders (peer community members) are, hence, taking place via academic workshops and discourses to refine prospective actions. The emerging outcome is a standard in form of submission guidelines that are piloted, motivated, and published in a special issue to be subsequently imposed on authors and reviewers of conferences, proceedings, and journals aiming for the fertile evolution of the DK Base.

This quasi-standard (or meta-artefact) addresses and defines the Problem Space (PS) and Solution Space (SS) as well as their relationship as expressed by Evolution (EV) as the three main DK components. It further introduces three measures to better "plan, coordinate, and communicate complex design research activities over time and space" [4]:

- Fitness is the degree of effectiveness, efficiency, and normative prescriptiveness in which a DSR solution in the SS has solved the targeted aspects of its real-world PS. While fitness-for-use focuses on current contexts, fitness-for-evolution considers the solutions' adaptability to potential dynamic changes.

- Confidence is the degree to which evaluation methods applied (EV) have assessed and confirmed the solution quality within an SS in respect of targeted PS aspects by the DSR project's interventions. Account, if possible, ought also to be taken of dynamically changing impacts over time.

- Projectability is the degree of how well a DSR project in the DK knowledge base (as grounded in its situational PS environment and objectives) may align to future research contexts and goals. 
To assist in this endeavor (Figure 2, method 1), Baskerville and Pries-Heje [11] propose a 'projectability serving language' and process logic for DSR projections. Having demonstrated it in an IT Project Management setting, they express the need for "further research to examine other frames of logic for worldmaking projections of social and organizational design artifacts". They also suggest a matrix to differentiate so-called 'actual real worlds' (ARWs) and 'future possible worlds' (FPWs) further for accommodating vertical (theoretical-to-empirical/practical generalizability) and horizontal (theoreticalto-theoretical) projectabilities to enable the recognition and transparency of "how design theories project not only artifacts into possible worlds but also design theories themselves" [11].

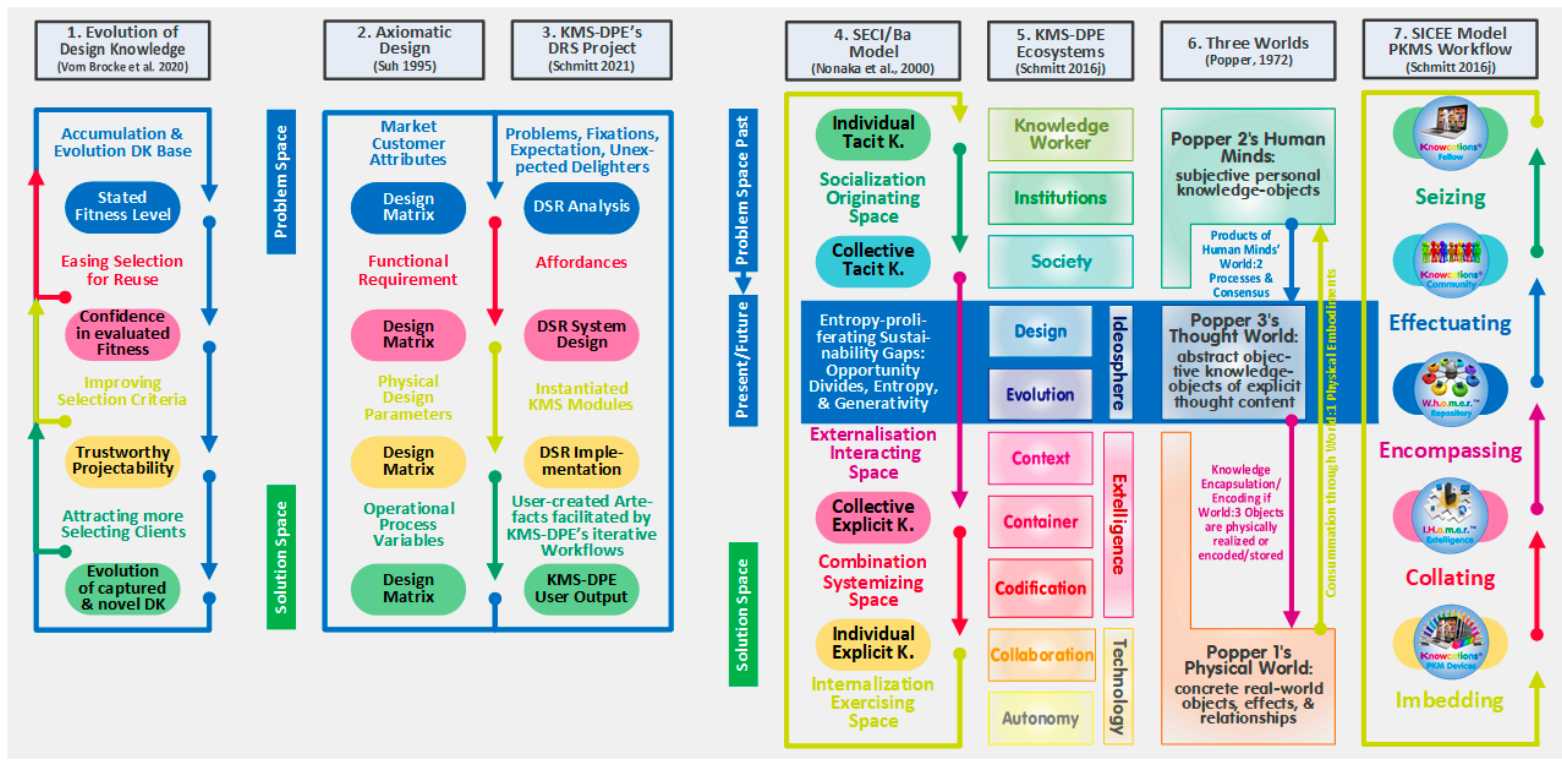

Figure 2. Visualization and Alignment of Selected Design and Problem-Solving Methodologies applied in this Article.

The PKMS case study to be introduced is supporting these propositions as it also aims to explain how its employed "design theories and design principles, as prescriptive constructs, imply intentionality for operation in other places or times" [11].

\section{Artefact, Evaluation, Diffusion, and Needs Issues Defining the PKMS's DSR Space}

The matters raised and remedies proposed suggest to revert back to an earlier article "Design Science Research for Personal Knowledge Management System DevelopmentRevisited" [12] where, in 2016, the DSR research paradigm-in this novel PKMS-related context-was presented for justifying the project's compliance with established DSR guidelines [9] and methodologies [10] and as evidence for easing the acceptance of follow-up submissions "as valuable, rigorous, and publishable in IS [Information Systems] research outlets" $[10](3,5)$ rather than defending their underlying research paradigm on an ad hoc basis every single time.

The DSR paradigm [9] and its aim for theory effectiveness expect designs to be purposeful, both in terms of utility (content) and communication (presentation) to an audience [13]. As a consequence, relevant existing, as well as emerging, external research findings, methodologies, and practices need to be explored and potentially integrated for continuous thorough design evaluation. Prior publications complementing the KM development have, hence, seized numerous opportunities over the last years to benchmark the PKMS's envisaged affordances and impacts to notions from the KM and related fields to be referred to later (as they relate to the issues discussed in Sections 2 and 3).

The ensuing complementing conceptual analyses and DSR methodologies (DSRM) have advanced the novel PKMS concept and prototype development by favoring person- 
alized, generative, negentropic, and community-based KM/KMS agendas as well as by allowing for a fruitful co-evolution with traditional institutional solutions (OKMS).

Accompanying articles have been presented and published to inform and get feedback in respect to the continually evolving PKMS design and artifacts (including anticipated technological, societal, organizational, and individual impact) contributing to the recent crafting and drafting of a desirable and viable KMS/Sustainability Vision [14].

This vision responds to the urgency for technological and educational interventions to combat opportunity divides as also expressed by the Sustainable Development Goals (SDG): as part of a broader goal on infrastructure, industrialization, and innovation, the SDGs commit to "significantly increase access to ICTs [information and communication technologies] and strive to provide universal and affordable access to the internet."

Given the advanced saturation levels in terms of mobile penetration, internet accessibility has been a logical focus. However, "while digital technologies have been spreading, digital dividends have not. [ . . . ] Technology can make workers more productive, but not when they lack the know-how to use it" [15].

The PKMS approach, hence, reframes and personalizes conventional KM intentions and design issues in the context of more viable cognitive and economic processes and reduces counter-productive unsustainable impacts while conserving individual and institutional energies and resources for fostering competencies and thrivability.

Figure 3 provides a bird's eye perspective of the PKMS as-what has been referred to as-a Digital Platform Ecosystem (DPE) [14,16]. It "depicts individual social actors (left) with their decentralized Personal KMS devices as members of the PKMS user community. The anti-clockwise workflow shows that the voluntary shared individual content is centrally synthesized and curated (top-right) before it is fed back to the community. It may also be repurposed as learning assets to foster personal learning environments (PLE) which comprise self-developmental activity spaces which encourage the reusing, remixing, and sharing of learning resources [17]. Adding to the broader DPE context are further interactions with organizational knowledge and learning management systems (OKMS, LMS) (top-middle-and-right)" [14].

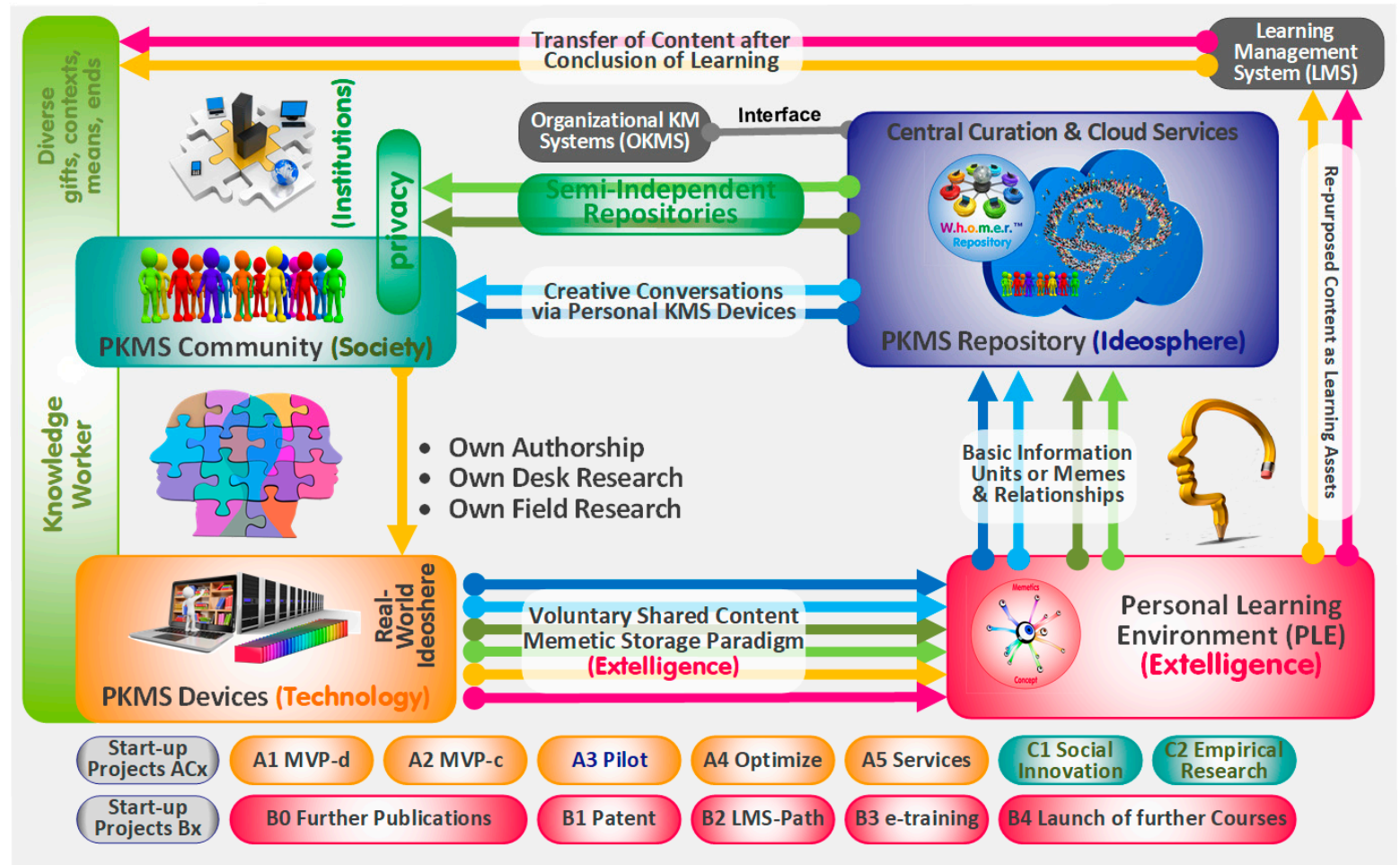

Figure 3. Generative PKMS/DSR Design as a Digital Platform Ecosystem (DPE) [14] (DPE notion based on [16]). 
The areas termed knowledge worker, technology, extelligence, ideosphere, and society refer to five of six PKMS ecosystems (plus institutions, Figure 2, method 5) which are also assisting in positioning workflows (Figure 2, methods 4, 6, and 7) and PKMS publications, and in creating supportive educational frameworks. The further differentiated projects (bottom) are to be referred to later.

\section{PKMS Case Study}

Section 4 provided a brief overview of the PKMS concept and workings. As its problem and solution space combines economic, social, and technological aspects in increasingly volatile, uncertain, complex, and ambiguous contexts, the design of such a generative KMS presents a "wicked" challenge, defined as open-ended in the sense that it is "illdefined and characterized by incomplete, contradictory, and changing requirements and complex interdependencies and that the information needed to understand the problem depends upon one's idea for solving it" [18]. The desirable sustainability KMS vision article recently published [14] has recapitulated and further rationalized the novel approach and its affordances and functionalities.

A DSR undertaking of this magnitude needs to monitor progress and 'theory effectiveness' systematically and systemically. With the concept and system "in a continuous flux of development", for example, "the feedback from publications [has emerged as one] determinant of quality assurance with the peer reviewers and audiences unconsciously taking up the role of an extended multi-disciplinary development team" [12].

The publications have, thus, been motivated by these benefits although-as to be presented in the discussion-also fully assist the proposed guiding principles (fitness, confidence, and projectability) alluded to in Section 3. The remainder of the article will focus on these meta-aspects and synergies.

\subsection{General Design Path Taken for Conceptualizing Novel Artefacts}

Table 1 summarizes the three iterative cycles which are driving the PKMS design; they have been detailed in the 'DSR revisited' article (2016) referred to earlier [12]. While the left column shows Hevner et al.'s DSR guidelines, the two columns on the right (as manifestations of G2) had emerged as a best practice/heuristic from the project work carried out earlier. The middle column demonstrates the focus on the individual by aiming for an affordable, decentralized (P)KMS rather than its conventional organizational costly OPKS counterpart. The right column provides a sub-cycle for each of the PKMS's Fx-phases and the needs of: taking account of KM's intangible nature (A), applying a complexity-reducing 'write-only-after-you-can-picture-it' approach, and keeping track of (B), consistency of, and referential integrity across the artefacts created (C), verifying functionality with ITand-paper-based testing (D), effectively informing and getting feedback (E), maintaining artefacts and content to easily fit in with new developments in other Fx-Gx-phases.

Table 1. PKMS Design as an Iterative Heuristic Search Process.

\begin{tabular}{lll}
\hline DSR Guidelines [9] & PKMS Design Cycles/Foci [12] & A-B-C-D-E-F Steps [12] \\
\hline G1 Design as an Artefact & F1 One's Personal Motivations, Burdens, Obstacles & Step A: Analogizing and metaphors \\
\hline G2 Design as a Search Process & F2 One's Knowledge-related Playing Field & Step B: Blueprinting and visualization \\
\hline G3 Problem Relevance & F3 One's Knowledge-related Capitals to develop & Step C: Conceptualizing and integration \\
\hline G4 Research Rigor & F4 One's Contributions to the Progress of the World & Step D: Demonstrating via prototypes \\
\hline G5 Research Contributions & $\begin{array}{l}\text { Comment: “One” refers to individual knowledge } \\
\text { workers as the PKMS's primary client base }\end{array}$ & Step E: Evaluating by peer reviews \\
\cline { 2 - 3 } G6 Design Evaluation & & Step F: Facilitating for innovation \\
\hline
\end{tabular}


The results of these iterative undertakings (mostly open access) are shown in Table 2. It lists the thirty Scopus/WoS-indexed conferences and journals, each with a time stamp. A preceding number indicates peer-reviewed presented posters, extended abstracts, nonScopus/WoS-indexed conference papers, and journal articles that may have led to the subsequent indexed article $(<)$ or have addressed complementary issues $(+)$. Each of them has a particular focus within the category, although they share a common KMS development scheme.

Table 2. Chronology of PKMS Publications Clusters: Ecosystems and Design Space.

\begin{tabular}{|c|c|c|}
\hline $\begin{array}{l}\text { Ecosystem } \\
\text { (Figure } 2 \text { (Method 5) } \\
\text { and Figure } 3 \text { ) }\end{array}$ & Problem Space & Solution Space \\
\hline Society & 1 & $3<$ Procedia-ICKM:2016h \\
\hline Institutions & $\begin{array}{l}1 \text { + ProWM:2017a } \\
1 \text { < JEIEE:2018a (non-indexed) }\end{array}$ & $\begin{array}{l}1<\text { ICKCCM:2016d } \\
\text { ISO 30401-KMS (under review) }\end{array}$ \\
\hline Knowledge Worker & $1<$ JIKM:2015f & $1+$ Sustainability:2018b \\
\hline $\begin{array}{l}\text { Technology } \\
\text { (Autonomy) }\end{array}$ & 3 + IEEE-NextComp:2017e & $\begin{array}{l}\text { InformSciJ:2017d } \\
\text { InformSciJ:2019b } \\
1 \text { < InformSciJ:2020e }\end{array}$ \\
\hline $\begin{array}{l}\text { Technology } \\
\text { (Collaboration) }\end{array}$ & $\begin{array}{l}\text { ACM:2012a } \\
1<\text { ICEL:2013b } \\
1 \text { < InformSciJ:2015d } \\
1<\text { LNCS/AISC:2016c }\end{array}$ & $\begin{array}{l}1<\text { LNCS/ICCCI:2017g } \\
\text { ICICKM:2018d } \\
\text { EJKM:2019c } \\
2<\text { Kybernetes:2020f }\end{array}$ \\
\hline $\begin{array}{l}\text { Extelligence } \\
\text { (Codification) }\end{array}$ & $\begin{array}{l}\text { IMSCI:2015g } \\
1+\text { LNCS/AISC:2016a }\end{array}$ & $1<$ JTKS:2015i \\
\hline $\begin{array}{l}\text { Extelligence } \\
\text { (Container) }\end{array}$ & $2<$ SIST:2016f & $\begin{array}{l}\text { ICEL:2017c } \\
\text { IEEE-NextComp: 2019f }\end{array}$ \\
\hline $\begin{array}{l}\text { Extelligence } \\
\text { (Context) }\end{array}$ & $\begin{array}{l}\text { Topic planned: Interdisciplinary } \\
\text { Knowledge Organization }\end{array}$ & this article \\
\hline $\begin{array}{l}\text { Ideosphere } \\
\text { (Evolution) }\end{array}$ & $\begin{array}{l}1<\text { LNCS/AISC:2016b } \\
\text { IJMO:2020b }\end{array}$ & $\begin{array}{l}1<\text { ECKM:2019d } \\
1<\text { Sustainability:2021a }\end{array}$ \\
\hline $\begin{array}{l}\text { Ideosphere } \\
\text { (Design) }\end{array}$ & $\begin{array}{l}2<\text { InformSciJ:2016j } \\
2<\text { IC3K:2014h }\end{array}$ & $\begin{array}{l}1<\text { Kybernetes:2019 } \\
\text { eEntropy:2020c }\end{array}$ \\
\hline Total Publications & $18+13$ Scopus/WoS-indexed & $13+17$ Scopus/WoS-indexed \\
\hline
\end{tabular}

\subsection{PKMS Project Progression versus DSRM Entry Points}

Figure 4 follows Peffer et al.'s DSRM phases [8-10] representing entry points and their related activities (left columns). All four entry points (problem-centered, objectivecentered, design and development-centered, and client/context-centered initiation) have been simultaneously addressed from the start of the PKMS project. Accordingly, the DSRM's activities commenced incrementally and iteratively. Applying Scholz's ninestep SVIDT-methodology [19] retrospectively (originally, it is conceptualized for forwardlooking analysis and planning) provided an opportunity to "reflect on and further validate the 'theory effectiveness' in a reverse-engineered manner from the proposed KMS solution back to the initial needs assessment". The multi-colored table (top-right) indicates parts of the results [20] including the envisaged PKMS designs/solutions resembling three interdependent and closely interacting development sub-projects. 


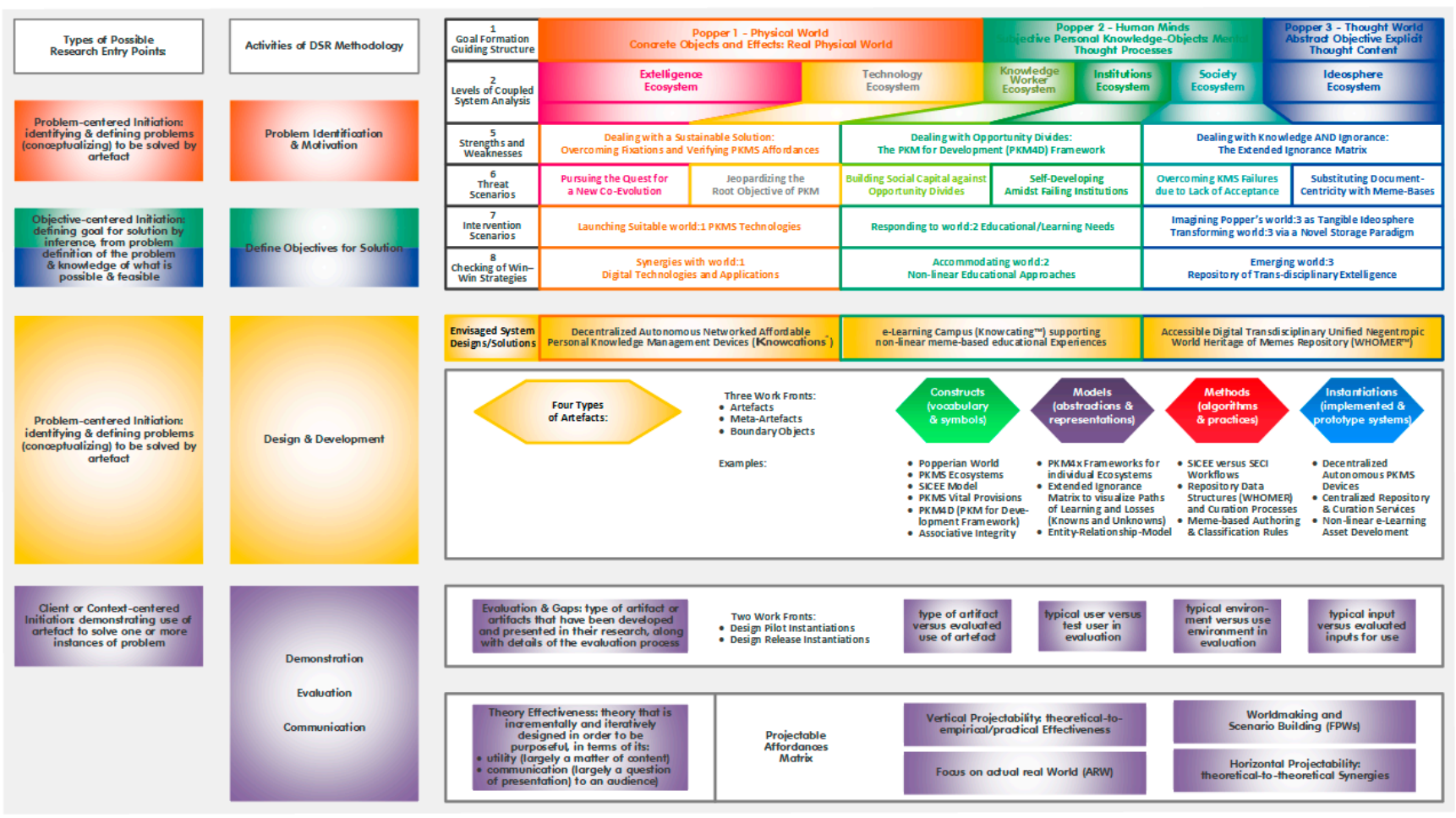

Figure 4. DSRM Process Landscape for the novel Generative PKMS Project (DSRM based on [10]).

\subsection{DSR Artefact Creation and Extension in the PKMS Development Scenario}

March's and Smith's differentiation of artefacts still holds (Figure 4, middle yellow section and Figure 1): Building on a basic specialized domain vocabulary, a shared conceptual language characterizes phenomena (constructs, e.g., terms, entities, attributes, types, or constraints) which may form the base to express relationships among them to describe higher-order complexes and utilities for capturing the structure of reality (models, e.g., tasks, situations, or artefacts). Constructs and models facilitate defining steps for performing goal-directed activities (methods, e.g., processes, algorithms, heuristics). Some of these three types of artefacts may then be combined to be physically, virtually, or mentally operationalized in their environment and may yield evidence of fitness-for-purpose (instantiations, e.g., prototypes, products, or implementations intended to perform certain tasks) [21] (253,256-258).

Artefacts, especially when digitized, afford the collaborative construction of knowledge. Some artefacts may be assembled to form a subset (termed meta-artefacts) for facilitating the formation of and interaction with their elementary counterparts (e.g., application packages, ERP systems, or development environments) or for supporting IS development processes (e.g., systems development approaches, methods, techniques, and tools) [22] (575).

The PKMS's Digital Platform Ecosystem (DPE) (Figure 3) fits this category of a metaartefact/system as it is meant to accommodate social actors with highly diverse skills (gifts), expectations, and ambitions (ends) to gainfully use the DPEs' resources and generative potential (means) in their personal and local environment (contexts) [16,23]. It follows that any of the PKMS-relevant artefacts (see examples in Figure 4) may only apply to some of the three subsystem or ecosystem levels (Figure 3 and Table 2) and that cross-level interdependencies have to be catered for in the design processes.

The approach taken resembles axiomatic design principles (Figure 2, method 2). Suh's theory [24] is based on taking four perspectives covering: market/customer attributes and needs \{CAs\} (expressed in the PKMS project (Figure 2, method 3) as problems, fixations, expectation, and unexpected delighters), functional requirements of a design solution \{FRs\} 
(affordances), corresponding physical design parameters and elements of the realized solution \{DPs\} (instantiated KMS modules), and the operational system's process variables that satisfy the initial market/customer needs $\{\mathrm{PVs}\}$ (symbolized by PKMS artefacts a user may create by following the iterative PKMS workflows). The axiomatic methodology utilizes design matrixes as interfaces between the four perspectives with the aim of decoupling any requirements to facilitate independent CA-FR-DP-PV implementations for reducing complexity, time, and costs. In the PKMS project, the decoupling is achieved by utilizing its meta-framework based on Popper's notion of the three worlds (Figure 2, method 6 and Figure 4 top-right row) with their ten ecosystem clusters (Figure 2, method 5 and Table 2, column 1); each of the latter is uniquely defined and hosts either one of the 5 workflows or their connecting system components (Figure 2, method 7).

\subsection{DSRM Evaluation in the Internal and External PKMS Development Spaces}

The 'DSR revisited' article (2016) [12] gave early indications of the KMS's testing regime as a response to DSR guideline G6 (Table 1) covering analytical, experimental, and observational methods which have been continuously carried out with the design's and technological progress.

With the envisaged launch of the PKMS start-up venture and investment (based on an in-principle approval of a governmental board in a near-by entrepreneurship-supportive country), the testing agenda will further expand (see the twelve defined sub-projects at the bottom of Figure 3).

In respect to De Sordi et al.'s study [8], it seems that the evaluation codes used for their content analysis are primarily targeting the instantiated outputs of the DSR projects. The axiomatic design matrices, in contrast, are bridging the four CA- > FR- > DP- > PV- > DA gaps and are all aiming for linking the 'what needs to be achieved' with the 'how to achieve it'; as every output of any of the interim solutions immediately becomes an input to the next level looking for an answer, every element in such a chain also needs to be somehow quality assured.

In the PKMS's internal space, these controls have been carried out in line with the ABCDEF steps (Table 1). In particular, the extensive visualization (MS Visio) allows for exposing gaps and inconsistencies as well as for enabling a two or three-dimensional monitoring of the referential and associative integrity between all artefacts.

In the external space, peer reviews and audience feedback has been mentioned. However, novel artefacts ought to be credible and valid even before their submissions are reviewed. While credibility refers to trustworthiness and believability, validity reflects on or evaluates the accuracy of a concept or idea. When these artefacts are benchmarked against or combined with existing theories, schemes, models, or methods that interpret/address the same phenomena (termed theory triangulation), the results assist in further exposing discrepancies and/or avoiding potential bias [25]. This is the reason for the advice referred to earlier to explore and potentially integrate further existing or emerging research outcomes and also accounts for the publications (Table 2 to be re-clustered later). In this way, the prescriptive content of the PKMS project has been grounded on existing DK and validated against descriptive empirical, conceptual, and theoretical research findings.

\section{Discussion}

The multi-disciplinary feedback and scope of the conferences, venues, and journals provided motivation and reassurances for driving the PKMS project's progress. As to be discussed in this section, it also provides-as it seems-a rare type of contribution to the DSR and KM field. The following subsections link the PKMS case (Sections 4 and 5) to the disciplinary shortcomings and proposed remedies alluded to (Sections 2 and 3).

\subsection{PKMS Case versus Cumulative Design Knowledge Addressed in Empirical Studies}

Had the PKMS's SVIDT article [20] mentioned been published a few months earlier, it may have been included in De Sordi et al.'s study [8] as one of its WoS-indexed base 
articles. Its DSR publication path would have shown its 20 preceding Scopus-indexed articles (since 2012) without-at the time-its nine subsequent (2018-2021) Scopus-indexed (incl. 4 WoS-indexed) publications.

The currently published KMS-related content references a total of 492 unique external sources (Oct. 2021) and includes over 200 tables and figures. It, hence, is able to serve together with the passages of the cited and citing sources as one of the PKMS's test knowledge bases (see WHOMER in Figure 3), and it is also envisaged (in a repurposed reconfiguration of its meme-based representation) to constitute a test-pilot and release e-learning course (for knowledge management) in the complementing e-Learning Campus/LMS.

De Sordi et al.'s initial sample [8] of 92 articles (published in 57 different impact-factor journals), however, found that adequate evaluation processes occurred in only 13 (14\%) articles (based on a content analysis using the codes: use of the artifact, typical or test user, use environment, and inputs for use). As already addressed in Section 5.4, the evaluation codes seem to account mainly for the outcomes of the artefact and not for any interim solution connecting levels of axiomatic design matrices.

The study also deduced an artefact-type-related precedence hierarchy (as recapitulated in Figure 1) from the timeline of the citation-linked articles which-in the PKMS casewould not have reflected reality. The reasons are that the chronology of the publications does not necessarily mirror progress in reality due to: (1) the wait for particular publication opportunities, long review processes, delays between acceptance and publication, or rejected submissions; (2) the parallel approach taken with the ecosystem streams where some areas may depend on the publishing of others or where some areas' result states may have appeared less stable than others.

The latter concern turned out to be unnecessarily overcautious; only one of the papers needed to undergo a major revision. A 2014 conference paper [26] whose extended version was then published as an LNCS/AISC chapter in 2016 [27] drafted a first meta-framework based on, among others, Nonaka et al.'s SECI (socialization, externalization, combination, and internalization) and Ba model [28]. After incorporating the ecosystem perspective and Popper's three worlds [29], this framework had to be modified [12]. However, as alluded to in the KMS's Sustainability Vision article [14], such a first draft is a typical knowledge output (termed "Vision-1") at the first level of a complex, more iterative visioneering process [30].

The reported follow-through blockades or publication gaps (Section 2) resulting in the paucity of follow-up, in particular, and the completeness of design science research (dissemination), in general, would lessen if more complex DSR results would be communicated in a PKMS-project like fashion-confirming the recommendations put forward.

\subsection{Current KMS and Projectability as a Foreward Looking Means in DSR to Frame the Future}

"Projectability provides a forward-looking means to frame the future and, thereby, propagate the knowledge and artifacts that researchers develop in DSR" [11] (53). As to be argued in this subsection, the projectability of current KM theory and practice is severely impeded.

The SECI and Ba model [28] — mentioned in the previous Section 6.1-represents the centerpiece of one of the most widely cited theories in knowledge management: Nonaka's theory of organizational dynamic knowledge creation [31]. It provided an understanding of how to stimulate the sharing and explicating of individual tacit knowledge to benefit collective explicit knowledge (incl. institutions) in an iterative SECI loop which is feeding back to individual learning (Figure 2, method 4).

Introduced over 25 years ago, Nonaka provided guidance to tackle PSs in an era of information scarcity characterized by few sources/channels, high associated costs, and organizational risks of losing institutional memory and capacity (through, for example, employee turnover, retirements, and/or reengineering exercises). The rapid adoption of the SECI model in SSs benefitted from the increasing power of ICT affordances and their crucial role for IT-enabled sustainable innovation in knowledge economies and societies [32]. 
With affordable ICT structures, storage capacities, web, and cloud services steadily flourishing, the PS features have significantly shifted from information scarcity to "a never before experienced ever-increasing attention-consuming information abundance" [33] experienced by many as cognitive overload.

The effects are widening sustainability gaps in the form of opportunity ('digerati' and 'have-nots' [34]) and innovation divides [35] driven by, for example, accelerating information entropy [36], invisible work [37], structural holes [38,39], and undiscoverable public knowledge [40], all further systemically discussed in a prior paper [41]. As the current "traditional knowledge creation models were all devised in the bygone era of information scarcity" when "today's digital abundance and entropy were beyond their makers' comprehension" [23], their methodical repertoire neither provides for the detection of these risks nor adequate responses. KM's entropic drivers mentioned in this paragraph have probably done more harm to the cumulativeness and evolution of scientific extelligence and transdisciplinary scholarship than the causes cited in all the previous sections.

Consequently, the projectability of conventional KM heuristics to tackle these growing PSs is poor, since they are all grounded in a bygone information-scarce world and have more or less completely ignored the once-unimaginable realities of today [42]. Their-in this sense- - unfitness-for-evolution has, instead, led to restricting fixations in the technological innovation and academic discourses preventing a following-up on, for example, Bush's, Simon's, Popper's, or Nielsen's farsighted past forewarnings [29,43-45].

\subsection{KMS Case versus Prospective Guidance Based on Fitness and Projectability}

The recent 'Special Issue Editorial' cited in Section 3 aims to address DSR's "scarce reuse of extant contributions and the limited accumulation and evolution of DK" more systemically as the current "monolithic structure" of DSR's accumulating knowledge base is prone to more "rapid aging" and is scrambling to build "solutions to more complex real-world problems" [4] (521). As unfitness-for-use-and-evolution of current KM has been referred to and the fitness-utility model [46] has already been addressed in a prior PKMS paper [47], this subsection focuses on the Projectability in the KMS-context and the implications for Design Theory (DT).

The analogies and metaphors used by Baskerville and Pries-Heje to promote their 'projectability serving language' fit well with the ones' applied in the 2016-DSR article [12] citing Popper's worlds [29] as well as Gibson's and Briscoes digital ecosystems [48,49]. Further referenced are the 'Big-T and small-T theories' metaphors used to address problems of logic and objectivity in science which motivated $\mathrm{O}^{\prime}$ Raghallaigh et al.'s notion of 'Theory Effectiveness' [13].

Popper's Worlds notion [29] introduced three distinct but interacting spheres of reality differentiated in: (1) the physical real World: 1 with its concrete encoded or encapsulated knowledge objects (tangible bodies/things with their effects and relationships) which sustain the survival of the (2) human minds' World:2 with its subjective personal knowledge objects through consummation via humans' World:1 physical embodiments. Once human minds' mental products (ideas and notions) are explicated (3) they inhabit the thoughts world:3 as abstract objective knowledge-objects of explicit thought content. World:3 serves Popper's philosophy that only formulated thoughts may be shared; able to be judged objectively on their own, they become independent of their creators. Due to their abstract nature, world:3's knowledge objects need still to be resourcefully combined and instantiated in concrete physical world:1 objects / artefacts (textually encoded or non-textually encapsulated in material things) and may then influence other minds.

The resulting change is very well supported by the worldmaking metaphor introduced by Baskerville and Pries-Heje in their DSR's projectability context. Here, change is viewed as distances between an actual local real-world (realized ARW, factually describable) and future possible worlds (unrealized FPW, counterfactually expressible) "where projectability provides a forward-looking means to frame the future and, thereby, propagate the knowledge and artifacts that researchers develop in DSR" [11] (54). A counterfactual 
conditional is, for example: If the abstract intangible world:3 model had been instantiated as a tangible world: $3^{*}$ mirror version (SS), many unsustainable entropic effects could have been avoided (PS).

Conventional OKMS are based on monolithic, centralized, investment-intensive, and high-maintenance technologies and top-down, prohibitive institutional approaches which serve "a fairly homogeneous set of stakeholders and cultures, surroundings and resources, practices, and objectives." The PKMS, in contrast, features grassroots, bottomsup, lightweight, affordable, personal applications envisaged to serve a highly diverse user community (see Section 5.3: gifts, contexts, means, and ends) [23]. The anticipated projection, hence, extends to many more FPWs compared to conventional OKMSs. Evidence of a first actual projection will exist once the smaller current prototypes have been transformed during the upcoming start-up phase.

The ten (P)KMS ecosystems (Figure 3 and Table 2) further segment Popper's three worlds (Figure 4) and are able to also accommodate Nonaka's four knowledge types (tacit/explicit cross-referenced with individual/collective) and their four connecting SECI and Ba workflows (Figure 2, methods 4-7). Popper's world:3 is represented by the Ideosphere ecosystem and marks the mentioned entropy-proliferating blind-spot of the traditional KM models. The PKMS's design theories and principles, thus, are originating from ARWs.

As one of the key features/benefits in the desired FPWs is reduced attention-consuming entropy, the entropy-generating causes in the ARW have to be identified, and design interventions need to be defined to close the distance between ARW and desirable FPWs. For this purpose, the 'Big-T/small-t theory' notion [13] is expanded into a 'Big-K/small-k knowledge object' metaphor. Big-K represents the explicated products of the author's non-linear mental thought products (e.g., designers, scholars). As linguistical, more linear formulated knowledge objects, they accumulate in a personal 'pigeon-hole' of world:3 accessible only to the author until some of its objects may be combined and instantiated as world:1 artefacts. This Ideosphere ecosystem may be imagined as a highly integrated space that holds an individuals' explicated, cumulatively synthesized knowledge (self-created and learned) with its relationships but which also provides sufficient clues to the subjective matter still in his/her world:2 mind. There would be no need to duplicate any items (entropy) although conflicting versions of ARWs and FPWs may be entertained. "The [world:3] Big-T[/K] theory is critical to representing aspects of a reality, while the [world:1] small- $\mathrm{t}[/ \mathrm{k}]$ theory is critical to disseminating to an audience an understanding of that reality" [13] (121).

As small-ks become world: 1 objects of potential formal criticism, our internal filters are applied before dissemination. In scholarly settings, the scope of calls for papers (CfP), restricting word counts, and pressures to cite preferred subsets of academic artefacts shape the small-k submissions-biases subsequently potentially reinforced by editors and reviewers. Double-blind reviews compel authors to duplicate more of prior work (replication) at the expense of the 'wordcount' real-estate and the need to drop novel contributions or references (invisible work [37]). Multi/inter/transdisciplinary research suffers once these practices become engrained in disciplinary conferences, journals, and/or domains-as sometimes for decades [50] (knowledge siloes). Follow-up papers facing the same settings in other outlets may become detached from the authors' prior publications due to unreported gaps and the need to drop unwelcome self-citations (structural holes [38,39]). Follow-up papers may also leave out essential bridging components, revise or even contradict prior contributions (inconsistencies), wrongly cite references (untraceabilities), or cite not at all (plagiarism). Moreover, the granular connectivity generated by the authors (from idea to cited idea) is typically only preserved at the document level. In the accumulated repositories of indexed scholarly literature, these missing, erroneous, or too-highly-aggregated references result in undiscoverable and unnecessarily-too-difficult-to-trace public knowledge [40] (see 'cited by' and 'related articles' in Google Scholar). 
This fragmentation of one's Big-K 'gestalt' into small-k artefacts has persevered for ages, but its dimension is amplifying due to the massification of higher education, publishor-perish policies, and 'standing-on-the-shoulders-of-giants' replications.

If we add the expanding social media where publishing is as easy as reading (with neither editorial nor review filters nor curation) and where the dissemination of fake news and data is actively pursued, the unsustainability-in respect to the very attention human capacities and cognitive capabilities are able to master-becomes apparent.

Alternative FPWs currently focusing on Big-Data and Internet-of-Things applications will worsen the entropic situation as further data is automatically produced autonomously by software (bypassing Popper's three-worlds-cycle entirely with a loop inside world:1). At the same time, content creation, delivery, and distribution are being differentiated by the current network economies where platform algorithms unbundle the messages from their medium and de-construct them in order to re-construct/re-bundle them in unrestrained configurations [14,51].

Artificial intelligence (AI) aims to aid constrained human cognitive abilities by applying automatic tagging using standardized generic descriptors/schemas, sematic webs or knowledge graphs, and statistical data-driven methods based on massive data sets to train machine-learning algorithms (neural networks and deep learning) in the natural-language processing domain (NLP). Proficient in translating foremost smaller passages and communications, the latter struggles to grasp the ambiguity and context-relevance of extended academic conversations and writings (exemplified by the use of metaphors in this article); the "skeletal meaning" may come through without the "subtle but important nuances" and without the correct grammar of complex deliberations [52].

Although existing (ARW) and emerging (FPW) methodologies, as argued, may be unsuited to address the entropic PS, the PKMS's relationship with and its distance to these technologies still need to be strategically determined (SS) and technological projected (e.g., co-evolution, co-competition, or disruptive substitution as well as interfaces). As summarized in the sustainable vision article [14], the PKMS affordances (SS) were positively benchmarked against twelve vision quality criteria representing visionary, sustainable, constructive, and transformative principles [53] each cross-referenced with one of twelve features of general-purpose-technologies (GPT, characterized by transformational innovations that affect "both household life and the ways in which firms conduct business"). Accordingly, GPTs exert significant impact, technical improvement, productivity growth, and innovation spawning across uses, industries, and/or application sectors [54]. The PKMS, hence, can be projected as a disruptive technology (FPW). However, radical novelties often adopt a more 'emergent innovation' approach [55] to ease complex tensions between known established ARWs and unfamiliar FPWs (e.g., personal computer systems which adopted many terms from the book-age era). Accordingly, the PKMS has been conceptualized for a co-evolution with OKMS (Table 3).

The comprehensive summary given has exemplified a series of valued ARW entities and artefacts to be retained in the FPW (e.g., OKMS and SECI model). Due to its disruptive nature, it was also shown that the PKMS's material transition from the local world to an FPW may "involve deleting obsolescent or conflicting entities in the environment, such as old systems" [11].

While the fully functional material artefact (and its testing to further increase confidence) still needs completion, this section has demonstrated that projections and projectability evaluations allowing for conceptual and systemic design adjustments (for the meta-PKMS-DPE as well as for its user-supporting artefact creation affordances) can, nevertheless, be carried out in the iterative design cycles. 
Table 3. Synergies between PKMS-SICEE Model (meme-based) and OKMS-SECI Model (document-centric) (Figure 2).

\begin{tabular}{ll}
\hline SICEE Cycle (Top-down in Sequence 1 to 5) [56] & SECI Cycle (Sequence 1, 2, 3, 4) [20] \\
\hline 1. Seizing & 1. Socializing
\end{tabular}

Tacit or explicit memes representing atomic ideas or content from external sources, desk or field research, and creative conversations via PKMS succeed in competing for an individual user's limited attention span to be located, accessed, and contemplated.

For survival, memes either need to be spread by the spoken word from one world:2 host's mind to other world:2 hosts' brains/minds or

\section{Imbedding}

Memes found useful, might be subjected to collection, comprehension, (re-)composition, capturing, and secure storing in an individual's PKMS device as original or mutated versions to facilitate personal sensemaking.
2. Internalizing and continuing with 1 . Socializing

For survival, memes either need to succeed in competing for a living host's world:2 attention span (such as people, teams, corporations, or economies) to be [subjectively and tacitly] memorized until forgotten, or

\section{Collating}

Captured memes may be related to other stored memes to form symbiotic relationships to mutually support each other's fitness and to replicate together as memeplexes and knowledge assets for creative work, authorship, citation, classification, and voluntary sharing.

\section{Encompassing}

Memes or knowledge assets and their relationships voluntarily shared are aggregated and curated in a 'World Heritage of Memes Repository' (WHOMER) to eliminate redundancies and consolidate traceabilities for managing entropy and assuring associative integrity.

\section{Combining}

with the potential to mutate into new variants or form symbiotic relationships with other memes (memeplexes or knowledge assets) to mutually support each other's fitness and to replicate together.

\section{Externalizing}

Codified (encoded or encapsulated knowledge) via objective abstract world:3 objects in inanimate durable world:1 vectors (such as buildings, machines, products, software, storage devices, books, great art, or major myths) spreading at times unchanged for millennia,

5. Effectuating and continuing with 1. Seizing

WHOMER curating options provide support for creating e-learning assets and citation/reputation metrics to ease collective content access, understanding, retention, and re-use.
Not addressed: Entropy-Proliferating Space

Entropy-proliferating space as described by the dissemination of Big-K world:3 knowledge via differentiated small-k world:1 artefacts.

\subsection{KMS Case versus Prospective Guidance Based on Projectabilities}

Based on Baskerville's and Pries-Heje's 'projectability language' [11], the previous section has been able to extract the projectability consideration driving the PKMS's DSR activities. In addition to the processing logic for DSR projections (ARWs and FPWs), the idea of a matrix for accommodating vertical (theoretical-to-empirical/practical generalizability) and horizontal (theoretical-to-theoretical) projectabilities has been put forward [11].

Table 4 offers such a matrix by placing the peer-reviewed publications (as small-k PKMS knowledge objects and instantiations of the Big-K 'PKMS/OKMS' concept summarized in Section 6.3) in the relevant quadrants. As these publications address vertical (benchmarking against less abstract relevant artefacts) and horizontal (cross-referencing other design theories and principles) projectability, as well as their combined impact for worldmaking and scenario building, the distances between actual and possible worlds, and between context and technology, have been considerably narrowed. 
Table 4. Triangulations carried out with other relevant external Artefacts (references as shown in Table 2).

\begin{tabular}{|c|c|}
\hline $\begin{array}{l}\text { Vertical Projectability: Theoretical-to-Empirical/Practical } \\
\text { Effectiveness }\end{array}$ & Worldmaking, Scenario Building, and Visioneering (FPWs) \\
\hline $\begin{array}{l}\text { V1T: Network Communities \& Social Platforms } \\
\text { (InformSciJ:2017d) } \\
\text { V2K: Sustainable Development Goals/Digital Intelligence }(+) \\
\text { V2K: Appropriation vs. Participation, Thought Leadership }\left(^{*}\right) \\
\text { V4D: General-Purpose-Technologies \& Innovation } \\
\text { (ECKM:2019d) } \\
\text { V4D: CK-Theory \& Scaling for Innovation (Kybernetes:2020f) } \\
\text { V5E: SMEs \& Stage-Growth Models (JEIEE:2018a) } \\
\text { V5E: From DSR Project to Start-up Venture (+) } \\
\text { V5E: Promise and Trust Engineering (+) } \\
\text { V6C: KMS Ecosystems as Decontextualized Boundary Objects } \\
(+)\end{array}$ & $\begin{array}{l}\text { W2K: Twelve Dynamic Knowledge Creation Models } \\
\text { (EJKM:2019c) } \\
\text { W3A: Interdisciplinary Knowledge Organization (+) } \\
\text { W3S: Systems Dynamics \& Activity-Based Modeling } \\
\text { (IJMO:2020b) } \\
\text { W4D: Visioneering, Vision Quality Criteria (Sustainability:2021a) } \\
\text { W4D: DSR Explicability /Projectabiliy/Domain Evolution (this } \\
\text { paper) } \\
\text { W4D: ISO 30401:2018-KMS Standard }\left(^{*}\right) \\
\text { W5E: ISO 56000:2020 Innovation Management Standard (+) } \\
\text { W6C: Non-linear Personal eLearning Environments (+) } \\
\text { W6C: DPE: PKMS-OKMS-LMS Co-evolutions } \\
\text { (InformingSciJ:2020e) }\end{array}$ \\
\hline $\begin{array}{l}\text { Focus on actual real World (incl. fixations \& unsustainabilities) } \\
\text { (ARW) }\end{array}$ & Horizontal Projectability: theoretical-to-theoretical Synergies \\
\hline $\begin{array}{l}\text { F1T: Webs of Documents and Data (IEEE-NextComp:2017e) } \\
\text { F1T: Digital Threats Assessment (Sustainability:2018b) } \\
\text { F2K: Digital Scholarship/Curation \& Traceability (JTKS:2015i) } \\
\text { F2K: Experience Management Concepts (ProWM:2017a) } \\
\text { F3A: Hierarchy of Needs, Kano Model (Procedia-ICKM:2016h) } \\
\text { F4D: Design Science Research Guidelines (InformSciJ:2016j) }\end{array}$ & $\begin{array}{l}\text { H2K: KM Models \& Methodologies (JIKM:2015f) } \\
\text { H2K: Schools of KM \& Knowledge Assets (ICKCCM:2016d) } \\
\text { H2K: Informing Science Methodologies (InformSciJ:2015d) } \\
\text { H3S: Memetics (LNCS/AISC:2016a) } \\
\text { H3S: Entropy \& Generativity Models (Entropy:2020c) } \\
\text { H3S: Generativity \$ Fitness-Utility-Models (Kybernetes:2019e) }\end{array}$ \\
\hline $\begin{array}{l}\text { Legend: } \\
\text { F: Focus on actual real World } \\
\text { H: Horizontal Projectability (theoretical-theoretical) } \\
\text { V: Vertical Projectability (theoretical-practical) } \\
\text { W: Worldmaking and Scenario Building } \\
\text { * under review } \\
\text { + planned }\end{array}$ & $\begin{array}{l}\text { Legend: Main Emphasis on: } \\
\text { 1T: Technological } \\
\text { 2K: Knowledge, KM, Informing, Organization } \\
\text { 3A: Academic \& Educational } \\
\text { 3S: Systems Thinking } \\
\text { 4D: Design Science \& Innovation } \\
\text { 5E: Entrepreneurial } \\
\text { 6C: Co-evolution LMS-PKMS-OKMS }\end{array}$ \\
\hline
\end{tabular}

As an interconnected part of the cumulative body of DK and KM content, they are also able to better inform systematic literature reviews and content analysis studies such as the ones presented in Section 2. This would contribute to increasing the reported maturity level of the disciplines' knowledge bases (that is, of course, as much as the content and its necessary self-references-and-citations have survived the prior double-or-single-blind review processes).

\section{Conclusions}

This article contributes towards Baskerville's and Pries-Heje's call for "future research to adopt or adapt projectability concepts in proactively formulating new projections" and "to examine other frames of logic for worldmaking projections of social and organizational design artifacts" [11]. As longitudinal research (judging from its large number of associated publications compared to De Sordi's et al.'s 'DSR in Practice' study [8]), the PKMS project seems to be rather an exception than the rule and, hence, particularly suited to add to the projectability notion referred to.

Moreover, the novel PKMS system itself through its user community is expected to exert a significant impact in regard to the cumulative synthesis and heritage management of design knowledge and other domains: (1) the attention and cognitive capacity savings [44] due to negentropic knowledge structures may be used for more creative conversations and innovations, (2) the explication and relatedness of currently 'invisible work' [37] provide opportunities to engage with topics in more information-rich contexts referred to by Bush in describing his 'Memex' as the currently not handed down 'scaffolding' of publications, (3) the purging of 'structural holes' [38,39], 'undiscoverable public knowledge' [40], 
and 'knowledge islands or siloes' by an increase in more granular, shared, curated, and negentropic memetic objects and relationships will enable more efficient creative conversations [57] and promote the quantitative and qualitative cumulative evolution of DSR and other disciplines.

In the anticipated projected FPWs, the ideosphere itself is gradually transformed from its abstract, intangible, inaccessible world:3 gestalt into its world:3to1 mirror version to be instantiated as "a steadily growing (expanding community sharing existent and novel content), single (cloud-based), unified (transdisciplinary), negentropic (redundancyeliminating), concrete, tangible, accessible, and interrogatable archive of an up-to-date knowledge heritage" (WHOMER) [58]. To make this new 'interface' fit, the 'outer environment' needs to adapt potentially triggering disruptive effects.

While the DK-base advocators (Section 3) are simply threatening authors by not accepting their submissions for publications without providing the requested new 'yardsticks' (SS in FPW), this article has exemplified that the systemic thinking and publishing of projectabilities may well be in the self-interest of design science researchers and practitioners. To appeal to users' self-interest to become part of the PKMS community, the PKMS concept also adopts a series of 'interface' and service extensions which are expected to result over time in accumulating adoption rates with quasi-irreversible switching costs and positive externalities from supply-side learning and demand-side network effects $[14,54]$.

The next activities are to complement the academically oriented DSR project with an entrepreneurial counterpart (start-up venture), and further planned publications are marked with a (+) in Table 4.

Funding: This research received no external funding but has contributed to the positive researcherranking by South Africa's National Research Foundation (NRF) and its subsequent awarded general.

Institutional Review Board Statement: Not applicable.

Informed Consent Statement: Not applicable.

Data Availability Statement: Not applicable.

Acknowledgments: This project is self-funded. The University of Stellenbosch Business School thankfully is providing the funds for covering the costs to publish in open access.

Conflicts of Interest: The author declares no conflict of interest other than intending to make the PKMS 'Knowcations ${ }^{\circledR}$ ' a viable success.

\section{References}

1. Borgman, C.L. Scholarship in the Digital Age: Information, Infrastructure, and the Internet; MIT Press: Cambridge, MA, USA, 2010; ISBN 978-0-262-25066-5.

2. Simon, H.A. The Sciences of the Artificial; MIT Press: Cambridge, MA, USA, 1996; ISBN 978-0-262-26449-5.

3. Baskerville, R.; Baiyere, A.; Gregor, S.; Hevner, A.; Rossi, M. Design Science Research Contributions: Finding a Balance between Artifact and Theory. J. Assoc. Inf. Syst. 2018, 19, 358-376. [CrossRef]

4. Vom Brocke, J.; Winter, R.; Hevner, A.; Maedche, A. Special Issue Editorial-Accumulation and Evolution of Design Knowledge in Design Science Research: A Journey Through Time and Space. J. Assoc. Inf. Syst. 2020, 21, 9. [CrossRef]

5. Schuster, R.; Wagner, G.; Schryen, G. Information Systems Design Science Research and Cumulative Knowledge Development: An Exploratory Study. In Proceedings of the ICIS 2018-International Conference on Information Systems, San Francisco, CA, USA, 13-16 December 2018.

6. Mariano, S.; Awazu, Y. Artifacts in Knowledge Management Research: A Systematic Literature Review and Future Research Directions. J. Knowl. Manag. 2016, 20, 1333-1352. [CrossRef]

7. Opdenakker, R.; Lacerda, D.P.; Dresch, A.; Carin, C. Sustainability CfP Special Issue “Designing Artifacts/Tools for Increasing Sustainability". Available online: https://www.mdpi.com/journal/sustainability/special_issues/designing_artifacts (accessed on 29 August 2021).

8. De Sordi, J.O.; de Azevedo, M.C.; Meireles, M.; Pinochet, L.H.C.; Jorge, C.F.B. Design Science Research in Practice: What Can We Learn from a Longitudinal Analysis of the Development of Published Artifacts? Inf. Sci. Int. J. Emerg. Transdiscipl. 2020, $23,1-23$.

9. Hevner, A.R.; March, S.T.; Park, J.; Ram, S. Design Science in Information Systems Research. Manag. Inf. Syst. Q. 2004, 28, 6. [CrossRef] 
10. Peffers, K.; Tuunanen, T.; Rothenberger, M.A.; Chatterjee, S. A Design Science Research Methodology for Information Systems Research. J. Manag. Inf. Syst. 2007, 24, 45-77. [CrossRef]

11. Baskerville, R.L.; Pries-Heje, J. Projectability in Design Science Research. J. Inf. Technol. Theory Appl. 2019, $20,3$.

12. Schmitt, U. Design Science Research for Personal Knowledge Management System Development-Revisited. Inf. Sci. 2016, 19, 345-379. [CrossRef]

13. O'Raghallaigh, P.; Sammon, D.; Murphy, C. The Design of Effective Theory. Syst. Signs Actions 2011, 5, 117-132.

14. Schmitt, U. Reframing a Novel Decentralized Knowledge Management Concept as a Desirable Vision: As We May Realize the Memex. Sustainability 2021, 13, 4038. [CrossRef]

15. World Bank Group. World Development Report 2016: Digital Dividends; World Bank Publications: Washington, DC, USA, 2016.

16. Eck, A.; Uebernickel, F. Untangling Generativity: Two Perspectives on Unanticipated Change Produced by Diverse Actors. In Proceedings of the ECIS, Istanbul, Turkey, 12-15 June 2016; p. 35.

17. Rahimi, E. A Design Framework for Personal Learning Environments. Ph.D. Thesis, Delft University of Technology, Delft, The Netherlands, 2015.

18. Rylander, A. Design Thinking as Knowledge Work: Epistemological Foundations and Practical Implications. Des. Manag. J. 2009, 4, 7-19. [CrossRef]

19. Scholz, R.W. Digital Threat and Vulnerability Management: The SVIDT Method. Sustainability 2017, 9, 554. [CrossRef]

20. Schmitt, U. Rationalizing a Personalized Conceptualization for the Digital Transition and Sustainability of Knowledge Management Using the SVIDT Method. Sustainability 2018, 10, 839. [CrossRef]

21. March, S.T.; Smith, G.F. Design and Natural Science Research on Information Technology. Decis. Support Syst. 1995, 15, 251-266. [CrossRef]

22. Iivari, J. The IS Core-VII: Towards Information Systems as a Science of Meta-Artifacts. Commun. Assoc. Inf. Syst. 2003, 12, 37. [CrossRef]

23. Schmitt, U.; Gill, T.G. Gifts, Contexts, Means, and Ends Differing: Informing Task Scenarios to Serve Knowledge Workers' Needs in Dynamic Complex Settings. Inf. Sci. Int. J. Emerg. Transdiscipl. 2020, 23, 119-145. [CrossRef]

24. Suh, N.P. Designing-in of Quality Through Axiomatic Design. IEEE Trans. Reliab. 1995, 44, 256-264. [CrossRef]

25. Noble, H.; Heale, R. Triangulation in Research, with Examples. Evid.-Based Nurs. 2019, 22, 67-68. [CrossRef] [PubMed]

26. Schmitt, U. The Significance of 'Ba' for the Successful Formation of Autonomous Personal Knowledge Management Systems. In Proceedings of the 9th International Conference, Limassol, Cyprus, 6-8 November 2014; Papadopoulos, G.A., Ed.; Springer: Berlin/Heidelberg, Germany, 2014.

27. Schmitt, U. The significance of 'ba' for the successful formation of autonomous personal knowledge management systems. In Knowledge, Information and Creativity Support Systems; Kunifuji, S., Papadopoulos, G.A., Skulimowski, A.M.J., Kacprzyk, J., Eds.; Advances in Intelligent Systems and Computing (AISC); Springer: Berlin/Heidelberg, Germany, 2016; Volume 416, pp. 391-407. ISBN 978-3-319-27477-5.

28. Nonaka, I.; Toyama, R.; Konno, N. SECI, Ba and Leadership: A Unified Model of Dynamic Knowledge Creation. Long Range Plan. 2000, 33, 5-34. [CrossRef]

29. Popper, K. Three Worlds. The Tanner Lectures, Humanities Center, University of Utah, Salt Lake City, UT, USA. 1978. Available online: https:/ / tannerlectures.utah.edu/_resources/documents/a-to-z/p/popper80.pdf (accessed on 30 October 2021).

30. Kaiser, A. Towards a Knowledge-Based Theory of Developing Sustainable Visions: The Theory Wave. In Proceedings of the 50th Hawaii International Conference on System Sciences 2017, Waikoloa Village, HI, USA, 4-7 January 2017; pp. 4495-4504.

31. Nonaka, I.; Takeuchi, H. The Knowledge-Creating Company: How Japanese Companies Create the Dynamics of Innovation; University Press: Oxford, UK, 1995; ISBN 978-0-19-987992-2.

32. Shirazi, F.; Hajli, N. IT-Enabled Sustainable Innovation and the Global Digital Divides. Sustainability 2021, 13, 9711. [CrossRef]

33. Schmitt, U. Personal Knowledge Management Devices-The next Co-Evolutionary Driver of Human Development. In Proceedings of the International Conference on Education and Social Sciences (INTCESS14), Istanbul, Turkey, 3-5 February 2014; pp. 1081-1091.

34. Drori, G.S. Globalization and Technology Divides: Bifurcation of Policy between the "Digital Divide" and the "Innovation Divide". Sociol. Inq. 2010, 80, 63-91. [CrossRef]

35. Giebel, M. Digital Divide, Knowledge and Innovations. J. Inf. Inf. Technol. Organ. 2013, 8, 1-24.

36. Signer, B. What Is Wrong with Digital Documents? A Conceptual Model for Structural Cross-Media Content Composition and Reuse. In Proceedings of the International Conference on Conceptual Modeling, Vancouver, BC, Canada, 1-4 November 2010; Springer: Berlin/Heidelberg, Germany, 2010; pp. 391-404.

37. Star, S.L. This Is Not a Boundary Object: Reflections on the Origin of a Concept. Sci. Technol. Hum. Values 2010, 35, 601-617. [CrossRef]

38. Burt, R.S. Structural Holes and Good Ideas. Am. J. Sociol. 2004, 110, 349-399. [CrossRef]

39. Burt, R.S. Reinforced Structural Holes. Soc. Netw. 2015, 43, 149-161. [CrossRef]

40. Szostak, R.; Gnoli, C.; López-Huertas, M. Interdisciplinary Knowledge Organization; Springer: Berlin/Heidelberg, Germany, 2016; ISBN 978-3-319-30148-8.

41. Schmitt, U. (Neg)Entropic Scenarios Affecting the Wicked Design Spaces of Knowledge Management Systems. Entropy 2020, 22, 169. [CrossRef] [PubMed] 
42. Schmitt, U. Decentralizing Knowledge Management: Affordances and Impacts. EJKM 2019, 17, 114-130.

43. Bush, V. As We May Think. Atl. Mon. 1945, 176, 101-108.

44. Simon, H.A. Designing Organizations for an Information-Rich World; The Johns Hopkins Press: Baltimore, MD, USA, 1971.

45. Nielsen, M. Reinventing Discovery: The New Era of Networked Science; Princeton University Press: Princeton, NJ, USA, 2012; ISBN 978-0-691-14890-8.

46. Gill, T.G.; Hevner, A.R. A Fitness-Utility Model for Design Science Research. ACM Trans. Manag. Inf. Syst. (TMIS) $2013,4,5$. [CrossRef]

47. Schmitt, U.; Gill, T.G. Synthesizing Design and Informing Science Rationales for Driving a Decentralizing Knowledge Management Agenda. Inf. Sci. J. 2019, 22, 1-18. [CrossRef]

48. Gibson, J.J. The Theory of Affordances; Lawrence Erlbaum Associates: Hillsdale, PA, USA, 1977; volume 1.

49. Briscoe, G. Complex Adaptive Digital Ecosystems. In Proceedings of the International Conference on Management of Emergent Digital EcoSystems, Bangkok, Thailand, 26 October 2010; ACM: New York, NY, USA, 2010; pp. 39-46.

50. Brix, J. Exploring Knowledge Creation Processes as a Source of Organizational Learning: A Longitudinal Case Study of a Public Innovation Project. Scand. J. Manag. 2017, 33, 113-127. [CrossRef]

51. Bhatt, S. How Digital Communication Technology Shapes Markets: Redefining Competition, Building Cooperation; Springer: Berlin/Heidelberg, Germany, 2016; ISBN 978-3-319-47250-8.

52. Mitchell, M. Artificial Intelligence: A Guide for Thinking Humans; Farrar, Straus and Giroux: New York, NY, USA, 2019.

53. Wiek, A.; Iwaniec, D. Quality Criteria for Visions and Visioning in Sustainability Science. Sustain. Sci. 2014, 9, 497-512. [CrossRef]

54. Cantner, U.; Vannuccini, S. A New View of General Purpose Technologies. In Empirische Makroökonomik und mehr; Jena Economic Research Papers: Jena, Germany, 2012.

55. Peschl, M.F.; Fundneider, T. Theory U and Emergent Innovation: Presencing as a Method of Bringing Forth Profoundly New Knowledge and Realities. In Perspectives on Theory U: Insights from the Field; IGI Global: Hershey, PA, USA, $2014 ;$ pp. $207-233$.

56. Schmitt, U. Designing Decentralized Knowledge Management Systems to Effectuate Individual and Collective Generative Capacities. Kybernetes 2019, 49, 22-46. [CrossRef]

57. Levy, P. The Semantic Sphere 1; Wiley: New York, NY, USA, 2011.

58. Schmitt, U. A Back-Casting Knowledge Management Vision for a Digital Platform Ecosystem in Support of Thrivable Communities of Knowledge Workers. JDIH 2020, 92-109. [CrossRef] 